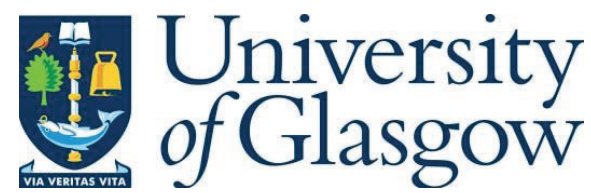

Sneddon, S., Mulvihill, D. M., Wielewski, E., Dixon, M., Rugg, D. and Li, P. (2021) Deformation and failure behaviour of a titanium alloy Ti-407 with reduced aluminium content: A comparison with Ti-6Al-4V in tension and compression.

Materials Characterization. 172, 110901. (doi: 10.1016/j.matchar.2021.110901)

There may be differences between this version and the published version. You are advised to consult the publisher's version if you wish to cite from it.

http://eprints.gla.ac.uk/228986/

Deposited on: 27 January 2021

Enlighten - Research publications by members of the University of Glasgow http://eprints.gla.ac.uk 


\title{
Deformation and failure behaviour of a titanium alloy Ti-407 with reduced aluminium content: a comparison with $\mathrm{Ti}-6 \mathrm{Al}-4 \mathrm{~V}$ in tension and compression
}

\author{
Scott Sneddon a , Daniel M. Mulvihill a, Euan Wielewski a, Mark Dixon ${ }^{\text {b }}$, David Rugg \\ b, Peifeng $\mathrm{Li}^{\mathrm{a}, *}$ \\ a James Watt School of Engineering, University of Glasgow, Glasgow, UK \\ ${ }^{\mathrm{b}}$ Rolls-Royce plc, PO Box 31, Derby, DE24 8BJ, UK \\ *Corresponding author's email: peifeng.li@glasgow.ac.uk (P. Li); Tel: +44 1413302703.
}

\begin{abstract}
The titanium alloy Ti-407 (Ti407) is a new alloy being considered for single load to failure applications where energy absorption is a key requirement. This work characterised the deformation and failure mechanisms of Ti407 in uniaxial tension and compression at quasi-static and increased strain rates. The results are compared with equivalent tests on Ti-6Al-4V (Ti64) to provide a benchmark. The stress-strain data under each condition reveals reduced strength but significantly increased ductility in the Ti407 alloy compared to Ti64. The reduced aluminium content in Ti407 is thought to allow additional dislocation motion and delay crack initiation and propagation. The crystallographic texture analysis on deformed specimens further suggests that in response to an applied stress, Ti407 proves more sensitive to texturing and exhibits
\end{abstract}


greater grain elongation and rotation in comparison to Ti64. Its ability to accommodate significantly more deformation before failure (than Ti64) will provide opportunities for improved impact energy absorption performance, as well as improved machinability and formability (and potentially lower manufacturing cost).

Keywords: Titanium alloy; Mechanical property; Texture; Strain rate; Deformation; Failure. 


\section{Introduction}

Titanium alloys are widely used in the aerospace industry due to their superior strength to weight ratio and corrosion resistance. The well-balanced strength and ductility have made Ti-6Al-4V (Ti64) one of the most versatile titanium alloys. High manufacturing costs related to high-temperature forming and subsequent machining are a drawback of Ti64 despite its attractive properties $[1,2]$. Ti64 is found in applications with a primary in-service failure mode involving a single load to failure. It is thus envisaged that reduced strength and increased ductility will provide improved performance in such applications, whilst significantly reducing manufacturing costs. Recent studies showed that a new titanium alloy Ti-407 (Ti407) benefits from significantly reduced flow stress during forming and increases tool life by more than $50 \%[3,4]$. Moreover, the reduced beta transformation temperature of Ti407 may reduce manufacturing costs. However, the deformation mechanisms associated with this alloy are not yet understood.

Ti407 differs from the traditional alpha-beta titanium alloys via a change in the material composition. The reduced aluminium content in Ti407 results in medium strength and high ductility. The reduced aluminium content weakens the role of aluminium solute atoms as obstacles against dislocation movement and consequently provides opportunities for improved machinability, formability and energy absorption capability during impact events. Like Ti64, Ti407 is a two-phase titanium alloy consisting of a primary aluminium-stabilised alpha phase and a secondary vanadium- 
stabilised beta phase $[3,5]$. The primary alpha phase exists as an anisotropic hexagonal close-packed (HCP) unit cell and the beta phase as a body-centred cubic (BCC) unit cell. Typically, the primary alpha phase is $\sim 90-95 \%$ by volume at room temperature and thus dominates the physical and mechanical properties in the alloy while the beta phase can be assumed as negligible $[5,6]$. The alpha phase has distinct anisotropic properties resulting from the inherent anisotropy of its HCP crystal structure [7]. The anisotropic behaviour of alpha titanium provides opportunities to specifically texture the alpha phase to maximise the macroscopic response of the material for specific applications $[8,9]$.

Alpha titanium primarily deforms by slip on preferential slip systems known collectively as $<a>$ type slip. This group of slip systems consists of basal $\{0001\}$, prismatic $\{10 \overline{1} 0\}$ and pyramidal $\{10 \overline{1} 1\}$ planes in directions $<11 \overline{2} 0>$. Non- $<a>$ type slip mechanisms occur at higher critical resolved shear stress (CRSS) than $<a>$ type slip $[5,10]$. It has been found that in alpha titanium the CRSS for $<_{c}+a>(474 \mathrm{MPa}$ on the pyramidal plane) is significantly greater than that for $<a>(209$ and $181 \mathrm{MPa}$ on the basal and prismatic planes, respectively) [11]. Thus, non- $<a>$ type slip systems are less common. However, $\langle c+a>$ slip is possible under high stress and strain rate conditions. Dynamic testing in alpha-beta titanium alloys may activate the $<_{c}+a>$ slip systems and is commonly accompanied by deformation twinning. The crystallographic features and mechanical response associated with the Ti407 alloy are not well 
established and there is little published literature available $[3,12]$. Therefore, more data is needed to quantitatively assess some of the proposed advantages of Ti407.

The aim of the study reported here is to characterise both macroscopic mechanical response and microscopic texture of Ti407 alloys. A combination of uniaxial tension and compression tests were conducted (to failure) at two strain rates. Post-test analysis techniques such as electron backscatter diffraction (EBSD) were used to characterise the deformation mechanisms and determine texture evolution under varying strain conditions. Equivalent tests were carried out on Ti64 alloys to provide a datum for comparison because Ti64 is the presently used industry standard.

\section{Experimental procedure}

\subsection{Materials}

The Ti64 and Ti407 material manufactured by TIMET UK Limited was supplied in plate form of approximately $0.5 \times 0.5 \mathrm{~m}^{2}$ and $0.2 \times 0.2 \mathrm{~m}^{2}$ respectively. The Ti64 ingot was produced with electron beam (EB) melting via cold hearth furnace followed by vacuum arc re-melting (VAR). Ingot open die forging using a combination of beta working and alpha-beta working made an intermediate plate. The Ti64 plate was unidirectionally (UD) rolled in the alpha-beta phase field followed by a creep flattening procedure. The Ti407 ingot was produced by electron beam single melting (EBSM) via cold hearth furnace. The Ti407 material was forged above the beta transus $\left(877^{\circ} \mathrm{C}\right)$ from the ingot through a square cross-section. The piece was then cross-rolled in the 
alpha-beta phase field to a rectangular cross-section. The Ti407 material was finally subjected to solution treatment and aging (STA). The composition details for each alloy are listed in Table 1 along with the key physical properties.

\subsection{Pre-test microstructure characterisation}

Characterisation of the as-received Ti64 and Ti407 plates was performed on the plane orientated in the transverse direction (TD). The material surface was prepared for EBSD in scanning electron microscopy (SEM) through the traditional three-stage grinding and polishing procedures. This involved initial coarse grinding with a diamond disc, fine grinding with composite pad and diamond suspension, and finally a chemical/mechanical polish with neoprene pad and colloidal silica solution. The microstructure of each alloy was first examined in a Carl Zeiss Sigma variable pressure analytical SEM with a $20 \mathrm{kV}$ electron beam and in a backscattered electron (BSE) detection mode. The crystallographic texture was then characterised through EBSD in an FEI Quanta 200 environmental SEM. An initial large area scan of $100 \times$ magnification at $5 \mu \mathrm{m}$ step was applied over an area of about $2.5 \times 2.5 \mathrm{~mm}^{2}$ to characterise the macro-texture of each alloy. An inverse pole figure (IPF) map at $300 \times$ magnification and $0.5 \mu \mathrm{m}$ step for an area of $500 \times 500 \mu \mathrm{m}^{2}$ was then created, followed by a high-resolution scan at $1000 \times$ magnification and $0.25 \mu \mathrm{m}$ step for an area of $150 \times 150 \mu \mathrm{m}^{2}$. 


\subsection{Mechanical testing}

Tension specimens were wire electrical discharge machined (EDM) from each plate in the transverse plane (TD) along the rolling direction (RD) for Ti64 and rolling direction 1 (RD1) for Ti407. Flat dog-bone test pieces were produced with dimensions shown in Fig. 1(a). Cylindrical compression specimens (Fig. 1(b)) were wire EDM cut from each plate in the normal direction (ND) (Fig. 1(b)).

Uniaxial tension experiments were performed in an INSTRON 3367 electromechanical universal testing machine with flat serrated grips according to the ASTM E8 standard. The strain was measured directly from the specimen gauge section with an EPSILON 3542 axial extensometer until failure. Quasi-static and increased strain rate conditions were applied for strain rate sensitivity observations and to highlight if deformation mechanisms such as twinning become more frequent with increasing strain rate. Quasi-static rate tests were conducted at a constant crosshead speed $0.025 \mathrm{~mm} \mathrm{~s}^{-1}$ resulting in a strain rate of $\dot{\varepsilon}=0.001 \mathrm{~s}^{-1}$. Increased strain rate tests were performed at a constant speed $2.5 \mathrm{~mm} \mathrm{~s}^{-1}$ with a corresponding strain rate of $\dot{\varepsilon}=$ $0.1 \mathrm{~s}^{-1}$. Uniaxial compression tests were carried out on both materials at quasi-static $\left(0.004 \mathrm{~mm} \mathrm{~s}^{-1}\right)$ and increased $\left(0.4 \mathrm{~mm} \mathrm{~s}^{-1}\right)$ speed providing nominal strain rates of $0.001 \mathrm{~s}^{-1}$ and $0.1 \mathrm{~s}^{-1}$. The ZWICK ROELL Z050 universal testing machine was used with flat compression platens following ASTM E9. Displacement in compression tests was measured from the crosshead movement. 


\subsection{Post-test microstructure characterisation}

Fracture surfaces are an important indicator of the mode of deformation and failure in metals. The post-tension fracture surfaces and post-compression outer surfaces of each alloy were observed with an ALICONA InfiniteFocus profilometer. Image field scans were acquired at $5 \times$ magnification to produce $3 \mathrm{D}$ profiles of the tested Ti64 and Ti407 specimens.

EBSD analysis was employed to determine the crystallographic texture of the tested specimens and characterise the texture evolution of each alloy. The tested specimens were sectioned to reveal the TD plane for EBSD analysis via the three-stage preparation procedure as detailed in Section 2.2. An arbitrary region near the failure surface for tension or the centre for compression was selected for a high-resolution EBSD scan at $1000 \times$ magnification in steps of $0.25 \mu \mathrm{m}$ for an area of $150 \times 150 \mu \mathrm{m}^{2}$.

\section{Results and discussion}

\subsection{Microstructure and texture}

The Ti64 material is a production scale material for comparison with the new Ti407 product. The Ti64 alloy consists of a traditional UD rolled microstructure (Fig. 2(a)). Macro-zones of basal-transverse texture are separated by regions of nonuniform grain size with a random crystallographic texture in comparison (Fig. 3(a)). The previous work on a UD rolled Ti64 material [13-15] also found a similar microstructure of macro-zones with the $c$-axis perpendicular to the rolling direction 
separated with regions of randomly textured grains - a common feature of UD rolled Ti64.

The Ti407 exhibits a fine-grained equiaxed microstructure of primary HCP alpha grains dispersed in a BCC beta matrix (Fig. 2(b)), achieved through STA heat treatment procedures. Some micro-texture zones of similar orientations within bulk evenly distributed crystallographic texture are formed in Ti407 as a result of thermomechanical cross-rolling and recrystallization procedures (Fig. 3(b)). This feature is also commonly found in cross-rolled Ti64 plate [16].

\subsection{Deformation and failure under uniaxial tension}

The tension specimens were tested to failure at a quasi-static strain rate of $\dot{\varepsilon}$ $=0.001 \mathrm{~s}^{-1}$ and also an increased rate of $\dot{\varepsilon}=0.1 \mathrm{~s}^{-1}$. Fig. 4 shows the resulting stressstrain curves for the UD rolled Ti64 and cross-rolled Ti407 loaded in the rolling direction. At least three repeats of each condition were performed with one representative result shown for each case. The key average tensile properties are listed in Table 2. Both yield strength $\left(\sigma_{\mathrm{y}}\right)$ and ultimate tensile strength (UTS) for Ti407 are significantly lower than Ti64. Aluminium and vanadium provide solid solution strengthening to the alpha and beta phases in titanium alloys, respectively [7]. The reduced aluminium content in Ti407 decreases such strengthening mechanisms and therefore strength characteristics [17]. 
Both yield strength and ultimate strength increase with strain rate to a similar extent in both alloys while strain to failure $\left(\varepsilon_{f}\right)$ is reduced at a higher strain rate (Table 2). Thus, the strength properties of both materials rise with increasing strain rate at the expense of ductility. Titanium alloys exhibit strain rate sensitivity over nearly seven orders of magnitude up to a strain rate of $10^{4} \mathrm{~s}^{-1}$ consistent with some other HCP metals [18-22]. This trend is evident for numerous alloys including Ti64, Ti10-2-3, Ti550 and Ti15-3-3-3 spanning a broad range of microstructures. The detailed mechanism for this rate sensitivity behaviour is yet to be fully elucidated. A change in plastic deformation mechanisms from deformation slip at low strain rates to deformation twinning at high rates may account for increased strength at higher strain rates [23]. For a more limited range of alloys including commercially pure titanium, solute interactions with dislocations also drive strain rate effects on strength in a limited range of strain rates and temperatures for a given solute [24]. From the limited data at only two rates (Fig. 4), the strain rate sensitivity exponent $(m)$ was determined as $m=0.012$ for Ti64 and $m=0.023$ for Ti407 at strain $\varepsilon=0.03[22,25]$. Whilst in this study Ti407 exhibits apparent slight increases in rate sensitivity compared to Ti64, further testing at more strain rates would be required to confirm this given the inherent nature of scatter in these tests. At the modest strain rates and plastic strain hardening in this study, effects arising from thermal heterogeneities, such as adiabatic shear, are believed to be negligible. Titanium alloys have limited strain hardening and much of the apparent hardening is driven by progressive exhaustion of available slip systems and activation of new ones as 
temperature increases [26]. For Ti407 the stack-up of unusual composition with respect to slip system activity and propensity for twinning as a function of strain will be complex.

The onset of failure is inhibited and necking is extended in the Ti407, compared to Ti64 (Fig. 4). Fractography reveals clear evidence of a classic cup and cone ductile failure in Ti407 but a less ductile fracture in Ti64 (Fig. 5). This is likely due to additional dislocation motion permitted by a reduction in aluminium content in Ti407, which delays crack initiation and propagation in failure. Therefore, significantly higher tensile strains to failure are observed in the Ti407 alloy as compared to Ti64 under each strain rate condition (Table 2). However, the toughness values for Ti407 are broadly similar to those for Ti64 (Table 2) since the area gained under the stress-strain curve via greater ductility is lost through the reduction in strength. Grain boundary sliding through dislocation slip has been found to be responsible for intergranular crack initiation in titanium alloys at low strain rates [23]. The elastic energy accumulated in quasi-static testing can dissipate via these micro-cracks, avoiding stress accumulation and consequently delaying failure. The ductile nature of Ti407 can accumulate more plastic strain and dissipate more energy arising from micro-cracking at lower strain rates. Improved energy absorption is therefore observed in quasi-static rate tests in comparison to increased strain rate tests (Table 2). 


\subsection{Texture evolution under uniaxial tension}

Fig. 6 illustrates the post-deformation inverse pole figures of UD rolled Ti64 and cross-rolled Ti407 specimens under uniaxial tension at a strain rate of $\dot{\varepsilon}=0.001 \mathrm{~s}^{-1}$. The pole figures are compared between deformed and undeformed specimens for Ti64 (Fig. 7) and Ti407 (Fig. 8).

Undeformed Ti64 alloy exhibits a strong basal texture (Fig. 7(a)) due to the presence of basal textured macro-zones distributed throughout the microstructure (Fig. 3(a)). Quasi-static tensile deformation increases texturing particularly in the basal (0001) and prismatic (10 $\overline{1} 0$ ) poles (Fig. 7(b)). Regions of macro-zones of basaltransverse texture are separated with regions of non-uniform grain size (Fig. 6(a)), which is similar to the undeformed state shown in Fig. 3(a). This indicates significant resistance to deformation slip and subsequent grain rotation in the Ti64 deformed quasistatically, accommodating stress with minimal texture evolution until fracture.

Lower pole figure intensities are found in undeformed Ti407 than undeformed Ti64 (Figs. 7(a) and 8(a)). A more evenly distributed texture exists across the three primary alpha pole figures, similar to textures in cross-rolled Ti64 [27]. A significant increase in pole figure intensities is observed in the basal and prismatic poles through quasi-statically deforming Ti407 (Fig. 8(b)), like Ti64 (Fig. 7(b)). As shown in Fig. 6(b), grains in Ti407 are elongated parallel to the applied load with significant grain rotation, unlike the undeformed state in Fig. 3(b). This is likely because the 
additional dislocation motion in Ti407 results in greater grain elongation, more lattice rotation and increased texturing through deformation slip, in contrast to Ti64 where dislocation motion is inhibited by increased aluminium solid solution.

Twinning can be observed in both alloys, more so in Ti64 (Fig. 6). A further study would be required to characterise deformed Ti407 at increased magnification to determine the twinning saturation in the material.

\subsection{Compressive behaviour}

Compression specimens were plastically deformed at the quasi-static $\left(\dot{\varepsilon}=0.001 \mathrm{~s}^{-}\right.$

$\left.{ }^{1}\right)$ and increased $\left(\dot{\varepsilon}=0.1 \mathrm{~s}^{-1}\right)$ strain rates until failure occurred or until a high strain of 0.80 was reached. The stress-strain data for the UD rolled Ti64 and cross-rolled Ti407 is shown in Fig. 9 with the corresponding compressive properties listed in Table 3. At least four repeats of each condition were performed with one representative result shown. Note that for Ti407 four test repeats were conducted up to a maximum strain of 0.80 and one repeat until nearly $100 \%$ strain - all having no evidence of fracture.

Ti64 in compression exhibits increases in both ultimate compressive stress to fracture and accumulated plastic strain with increasing strain rate (Fig. 9 and Table 3) [17]. These flow stress characteristics are commonly reported with Ti64 in compression [28]. Increasing strain rate results in increased generation of dislocations and subsequent interactions in Ti64, thus delaying failure whilst accumulating increased stress [29]. Ti64 in compression experiences catastrophic shear failure. The fracture can 
be attributed to adiabatic shear mechanisms resulting in localised deformation, heating and failure of the material [29-31]. Ti64 in low rate compression clearly highlights fracture at approximately $45^{\circ}$ where maximum shear stresses are experienced (Fig. 10(a)). In a longitudinal section, the triaxial stress is a mixture of compressive and tensile states along the diagonal $\left(45^{\circ}\right)$ whereas hydrostatic compression occurs in the centre of a specimen [32]. Under increased rate compression, a conjugated shear fracture occurs in Ti64 where compressive failures intersect towards the centre of the specimen and propagated laterally (Fig. 10(b)). A combination of hoop stress on the equatorial plane and induced tensile stress coupled with maximum shear stress results in deformation in the form of an ' $\mathrm{X}$ ' shaped cross, observed on the fracture surface [33].

Ti407 in compression undergoes extreme resistance to fracture. No failure was recorded at the exerted strain $\varepsilon=0.80$ (Fig. 9). The macroscopic deformation in Ti407 specimens showed lateral barrelling transverse to the applied load until machine limitations were met (Fig. 10(c, d)), in contrast to catastrophic failure in Ti64. The increased strain rate has a less pronounced effect on flow stress in the Ti407 alloy (Fig. 9), potentially due to yielding of ductile grains reducing hardening effects gained from dislocation interactions. Compared to Ti64, a significant increase in ultimate strength, compressive strain to failure and toughness is expected in the Ti407 alloy through a highly ductile absorption of energy (Table 3). However, it should be noted that it is difficult to determine values for these metrics in the absence of failure. The values for T407 in Table 3 merely represent the maximum values reached when testing 
was terminated at the high strain $\varepsilon=0.80$. A high volume of dislocation motion is likely permitted in the Ti407 alloy to allow ductile slip mechanisms to persist to very high strains, thus resisting fracture.

Fig. 11 shows the IPF maps for the bulk Ti64 material compressed until failure and for Ti407 compressed until $\varepsilon=0.80$, both at $\dot{\varepsilon}=0.001 \mathrm{~s}^{-1}$. A significant volume of intragranular misorientation in grains with varying colour gradients arises in Ti64 due to substantial strain accumulation in each grain. Sub-grains potentially form with high volumes of micro-grains dispersed throughout the bulk material. Lateral grain elongation normal to the applied load occurs in the Ti64 alloy as strain accumulation in each grain results in slip. Low image quality maps are the evidence of potential regions of high dislocation density, particularly at grain boundaries where dislocation pile-up occurs.

An IPF map in the central region of a compressed Ti407 (Fig. 11(b)) clearly shows severe deformation throughout the microstructure with a subsequent low volume of indexed grains. The image quality map saturates the IPF map with dark regions, which may be due to the presence of high dislocation density in the corresponding regions [34]. Heavily deformed microstructures increase the difficulty for pattern indexing, and this leads to lower quality EBSD maps as shown in the Ti407, indicating high levels of deformation [35]. The indexed grains in Ti407 show no basal-transverse orientations. The higher propensity of Ti407 to deform by $\langle c+a>$ slip has been reported in a recent study [12]. It was suggested that the high degree of strain experienced is likely due to 
increased deformation along the c-axis. This may also explain the grain orientations in compression of Ti407. Grains in Fig. 11(b) may also have been preferentially orientated for prismatic slip.

\section{Conclusions}

The paper characterised the mechanical properties of a new titanium alloy (Ti407) in uniaxial tension and compression. Both quasi-static and increased strain rate tests were conducted. Equivalent tests were carried out on the commonly used aerospace alloy Ti64 to provide a datum for comparison. Test results were augmented by pre-test and post-test microstructure characterisation as well as optical observation of fracture surfaces. The conclusions were drawn as follows.

- In both tension and compression and at both strain rates, Ti407 exhibits a significantly greater strain to failure than Ti64 and this is likely due to the reduced aluminium content in Ti407 that promotes additional dislocation motion. In tension, Ti407 has significantly increased ductility (quasi-static strain to failure increase of $60 \%$ ), but reduced strength (quasi-static ultimate strength reduction of $34 \%$ ) in comparison to Ti64. The increase in ductility and reduction in strength combine to give similar toughness values for the two alloys. Ti407 exhibits a ductile cup and cone fracture, while the fracture surface in Ti64 is more typical of less ductile fracture. The ductility of Ti407 results from the microstructure and texture evolution. Significantly more grain elongation and rotation arise for Ti407 than for 
Ti64 under quasi-static tension. Extensive texture evolution is observed in Ti407, while limited texturing in Ti64.

- The response of both alloys to higher strain rate tension is similar: a moderate increase in strength together with a reduction in strain to failure. In compression, Ti64 fails in the usual way at $45^{\circ}$ to the compression axis due to maximum shear stresses, but Ti407 exhibits extreme resistance to fracture with no failure even at a high strain up to $\varepsilon=0.80$.

- Ti407 is highly ductile but with a strength reduction. However, its ability to accommodate large levels of deformation without failure suggest advantages in terms of both impact energy absorption and increased machinability/formability which can potentially reduce manufacturing costs. Further study is required to both alleviate and assess any implications arising from the reduced strength.

\section{Acknowledgements}

The authors gratefully acknowledge the financial support of Rolls-Royce plc and the University of Glasgow.

\section{Declaration of interests}

The authors declare that they have no known competing financial interests or personal relationships that could have appeared to influence the work reported in this paper. 


\section{Data availability}

The raw/processed data required to reproduce these findings cannot be shared at this time as the data also forms part of an ongoing study.

\section{References}

[1] J. Luo, M.Q. Li, W.X. Yu, H. Li, The variation of strain rate sensitivity exponent and strain hardening exponent in isothermal compression of Ti-6Al-4V alloy, Mater. Des. 31(2) (2010) 741-748.

[2] J.J. Xiao, D.S. Li, X.Q. Li, P. Ding, K. Zhao, X.Z. Huang, M.J. Xu, Process parameters optimization of Ti-6Al-4V alloy sheet during hot stretch-creep forming, Trans. Nonferrous Met. Soc. China 25(2) (2015) 420-428.

[3] Y. Millet, S. James, Y. Kosaka, R. Thomas, P. Garratt, Timetal® 407: A Titanium Alloy to Enable Cost Reduction, Proceedings of the 13th World Conference on Titanium2016, pp. 721-725.

[4] S. Sneddon, Y. Xu, M. Dixon, D. Rugg, P. Li, D.M. Mulvihill, Sensitivity of material failure to surface roughness: a study on titanium alloys Ti64 and Ti407, Mater. Des. (2020) 109438.

[5] G. Lütjering, J.C. Williams, Titanium, Springer, Hamburg, 2010.

[6] M.J. Donachie, Titanium: A Technical Guide, 2nd Edition, ASM International, 2000.

[7] C. Leyens, M. Peters Titanium ans Titanium Alloys, Wiley-VCH, Colonge, 2003.

[8] M.E. Nixon, O. Cazacu, R.A. Lebensohn, Anisotropic response of high-purity alpha-titanium: Experimental characterization and constitutive modeling, Int. J. Plast. 26(4) (2010) 516-532.

[9] Z. Zhang, T.S. Jun, T.B. Britton, F.P.E. Dunne, Intrinsic anisotropy of strain rate sensitivity in single crystal alpha titanium, Acta Mater. 118 (2016) 317-330. 
[10] L. Wang, Z. Zheng, H. Phukan, P. Kenesei, J.S. Park, J. Lind, R.M. Suter, T.R. Bieler, Direct measurement of critical resolved shear stress of prismatic and basal slip in polycrystalline Ti using high energy X-ray diffraction microscopy, Acta Mater. 132 (2017) 598-610.

[11] J.C. Gong, A.J. Wilkinson, Anisotropy in the plastic flow properties of singlecrystal alpha titanium determined from micro-cantilever beams, Acta Mater. 57(19) (2009) 5693-5705.

[12] Z. Kloenne, G. Viswanathan, M. Thomas, M.H. Lorreto, H.L. Fraser, A Comparative Study on the Substructure Evolution and Mechaniccal Properties of TIMETAL®407 and Ti-64, The 14th World Conference On Titanium, Nantes, 2019.

[13] M.R. Bache, W.J. Evans, Impact of texture on mechanical properties in an advanced titanium alloy, Mater. Sci. Eng. A 319 (2001) 409-414.

[14] T.B. Britton, S. Birosca, M. Preuss, A.J. Wilkinson, Electron backscatter diffraction study of dislocation content of a macrozone in hot-rolled Ti-6Al-4V alloy, Scr. Mater. 62(9) (2010) 639-642.

[15] D. Lunt, The effect of macrozones in Ti-6Al-4V on the strain localisation behaviour, The University of Manchester Manchester 2014.

[16] E. Wielewski, M.R. Arthington, C.R. Siviour, N. Petrinic, Characterising the effects of strain rate, crystallographic texture and direction of loading on the mechanical behaviour of Ti-6Al-4V, J. Dynam. Behav. Mater. 1(4) (2015) 462471.

[17] A. Fitzner, D.G.L. Prakash, J.Q. da Fonseca, M. Thomas, S.Y. Zhang, J. Kelleher, P. Manuel, M. Preuss, The effect of aluminium on twinning in binary alpha-titanium, Acta Mater. 103 (2016) 341-351.

[18] J.H. Giovanola, R.W. Klopp, D.A. Shockey, Modeling of microstructural effects on fracture processes at high loading rates, Southwest Research Inst. Report, 1992.

[19] M. Zakaria, X. Wu, Response of titanium alloys to high strain rate deformation, Mater. Sci. Technol. 21(2) (2005) 225-231. 
[20] K.T. Ramesh, Effects of high rates of loading on the deformation behavior and failure mechanisms of hexagonal close-packed metals and alloys, Metall. Mater. Trans. A 33(3) (2002) 927-935.

[21] Z. Wang, P. Li, Characterisation and constitutive model of tensile properties of selective laser melted Ti-6Al-4V struts for microlattice structures, Mater. Sci. Eng. A 725 (2018) 350-358.

[22] P. Li, N.V. Nguyen, H. Hao, Dynamic compressive behaviour of Mg foams manufactured by the direct foaming process, Mater. Des. 89 (2016) 636-641.

[23] W. Zhou, K.G. Chew, The rate dependent response of a titanium alloy subjected to quasi-static loading in ambient environment, J. Mater. Sci. 37(23) (2002) 5159-5165.

[24] H. Conrad, Effect of interstitial solutes on the strength and ductility of titanium, Progress in Materials Science 26(2-4) (1981) 123-404.

[25] L. Xiao, W. Song, M. Hu, P. Li, Compressive properties and micro-structural characteristics of $\mathrm{Ti}-6 \mathrm{Al}-4 \mathrm{~V}$ fabricated by electron beam melting and selective laser melting, Mater. Sci. Eng. A 764 (2019) 138204.

[26] F. Bridier, P. Villechaise, J. Mendez, Analysis of the different slip systems activated by tension in a alpha/beta titanium alloy in relation with local crystallographic orientation, Acta Mater. 53(3) (2005) 555-567.

[27] E. Wielewski, G.J. Appleby-Thomas, P.J. Hazell, A. Hameed, An experimental investigation into the micro-mechanics of spall initiation and propagation in $\mathrm{Ti}$ 6Al-4V during shock loading, Mater. Sci. Eng. A 578 (2013) 331-339.

[28] M. Arulselvan, G. Ganesan, A Study on Compression Test on Ti-6Al-4V in Various Strain Rates and Various Temperature, Int. J. Recent Technol. Eng. 2(4) (2013) 47-51.

[29] S. Sharma, A.N. Majila, V.M. Chavan, D.C. Fernando, R.J. Patel, S.N. Babu, Deformation response of Titanium alloy under static and dynamic loading, in: N.K. Gupta, M.A. Iqbal (Eds.), Plasticity and Impact Mechanics, Elsevier Science Bv, Amsterdam, 2017, pp. 1894-1900. 
[30] P.H. Li, W.G. Guo, W.D. Huang, Y. Su, X. Lin, K.B. Yuan, Thermomechanical response of 3D laser-deposited Ti-6Al-4V alloy over a wide range of strain rates and temperatures, Mater. Sci. Eng. A 647 (2015) 34-42.

[31] Q. Xue, M.A. Meyers, V.F. Nesterenko, Self-organization of shear bands in titanium and Ti-6Al-4V alloy, Acta Mater. 50(3) (2002) 575-596.

[32] P. Li, C.R. Siviour, N. Petrinic, The Effect of Strain Rate, Specimen Geometry and Lubrication on Responses of Aluminium AA2024 in Uniaxial Compression Experiments, Exp. Mech. 49(4) (2009) 587-593.

[33] W.S. Lee, C.F. Lin, Adiabatic shear fracture of titanium alloy subjected to high strain rate and high temperature loadings, J. Phys. IV 7(C3) (1997) 855-860.

[34] R.K. Gupta, V.A. Kumar, C. Mathew, G.S. Rao, Strain hardening of Titanium alloy Ti6Al4V sheets with prior heat treatment and cold working, Mater. Sci. Eng. A 662 (2016) 537-550.

[35] S.I. Wright, M.M. Nowell, S.P. Lindeman, P.P. Camus, M. De Graef, M.A. Jackson, Introduction and comparison of new EBSD post-processing methodologies, Ultramicroscopy 159 (2015) 81-94. 


\section{List of Tables}

Table 1 Chemical composition, density $\rho$ and transus temperature $T_{\beta}$ of Ti64 and Ti407 alloys.

\begin{tabular}{lcc}
\hline Attribute & Ti64 & Ti407 \\
\hline $\mathrm{Al}(\mathrm{wt} \%)$ & 6.0 & 0.85 \\
$\mathrm{~V}(\mathrm{wt} \%)$ & 4.0 & 3.90 \\
$\mathrm{O}(\mathrm{wt} \%)$ & 0.15 & 0.15 \\
$\mathrm{Si}(\mathrm{wt} \%)$ & - & 0.25 \\
$\mathrm{Fe}(\mathrm{wt} \%)$ & 0.15 & 0.25 \\
$\rho\left(\mathrm{kg} \mathrm{m}^{-3}\right)$ & 4420 & 4530 \\
$T_{\beta}\left({ }^{\circ} \mathrm{C}\right)$ & 996 & 877 \\
\hline
\end{tabular}

Table 2 Measured tensile properties of Ti64 and Ti407 alloys at different strain rates.

\begin{tabular}{cccccc}
\hline Alloy & $\begin{array}{r}\text { Strain rate, } \\
\dot{\varepsilon}\left(\mathrm{s}^{-1}\right)\end{array}$ & $\begin{array}{r}\text { Yield strength, } \\
\sigma_{\mathrm{y}}(\mathrm{MPa})\end{array}$ & $\begin{array}{c}\text { Ultimate strength, } \\
\text { UTS }(\mathrm{MPa})\end{array}$ & $\begin{array}{c}\text { Strain at } \\
\text { failure, } \varepsilon_{\mathrm{f}}\end{array}$ & $\begin{array}{c}\text { Toughness } \\
\left(\mathrm{kJ} \mathrm{m}^{-3}\right)\end{array}$ \\
\hline Ti64 & 0.001 & 929 & 964 & 0.174 & 16.18 \\
& 0.1 & 996 & 1011 & 0.151 & 14.49 \\
Ti407 & 0.001 & 593 & 639 & 0.279 & 16.87 \\
& 0.1 & 658 & 675 & 0.211 & 13.22 \\
\hline
\end{tabular}


Table 3 Measured compressive properties of Ti64 and Ti407 alloys at different strain rates.

\begin{tabular}{ccccc}
\hline Alloy & $\begin{array}{c}\text { Strain rate, } \\
\dot{\varepsilon}\left(\mathrm{s}^{-1}\right)\end{array}$ & $\begin{array}{c}\text { Ultimate strength, } \\
(\mathrm{MPa})\end{array}$ & $\begin{array}{c}\text { Strain at failure, } \\
\varepsilon_{\mathrm{f}}\end{array}$ & $\begin{array}{c}\text { Toughness } \\
\left(\mathrm{kJ} \mathrm{m}^{-3}\right)\end{array}$ \\
\hline Ti64 & 0.001 & 2125 & 0.54 & 71.5 \\
& 0.1 & 2216 & 0.57 & 78.2 \\
Ti407 & 0.001 & $2812^{*}$ & $0.80^{*}$ & $118.6^{*}$ \\
& 0.1 & $2824^{*}$ & $0.80^{*}$ & $120.7^{*}$ \\
\hline
\end{tabular}

* No failure occurred for Ti407 in compression; values given are the maximum recorded values before tests were stopped. 


\section{List of Figures}

Fig. 1 Dimensions and orientation of (a) flat tension specimen and (b) cylindrical compression specimen.

Fig. 2 SEM BSE images of the alpha (dark) and beta (bright) phases of (a) Ti64 and (b) Ti407 alloys in the TD plane.

Fig. 3 EBSD inverse pole figures of (a) Ti64 and (b) Ti407 alloys in the TD plane at two different magnifications.

Fig. 4 Representative nominal stress-strain curves of Ti64 and Ti407 alloys under uniaxial tension at different strain rates.

Fig. 53 3 profiles of the two matching fracture surfaces of (a) Ti64 and (b) Ti407 alloys under uniaxial tension at the strain rate $0.001 \mathrm{~s}^{-1}$.

Fig. 6 EBSD inverse pole figures in the TD plane of (a) Ti64 and (b) Ti407 alloys under uniaxial tension at the strain rate $0.001 \mathrm{~s}^{-1}$.

Fig. 7 EBSD pole figures of Ti64 alloys: (a) undeformed and (b) under tension at the strain rate $0.001 \mathrm{~s}^{-1}$. At $1000 \times$ magnification.

Fig. 8 EBSD pole figures of Ti407 alloys: (a) undeformed and (b) under tension at the strain rate $0.001 \mathrm{~s}^{-1}$. At $1000 \times$ magnification.

Fig. 9 Representative nominal stress-strain curves of Ti64 and Ti407 alloys under uniaxial compression at different strain rates.

Fig. $103 \mathrm{D}$ surface profiles of titanium alloys subjected to uniaxial compression at different strain rates: (a) Ti64, $0.001 \mathrm{~s}^{-1}$, (b) Ti64, $0.1 \mathrm{~s}^{-1}$, (c) Ti407, $0.001 \mathrm{~s}^{-1}$ and (d) Ti407, $0.1 \mathrm{~s}^{-1}$.

Fig. 11 EBSD inverse pole figures of (a) Ti64 and (b) Ti407 alloys subjected to uniaxial compression at strain rate $0.001 \mathrm{~s}^{-1}$. 

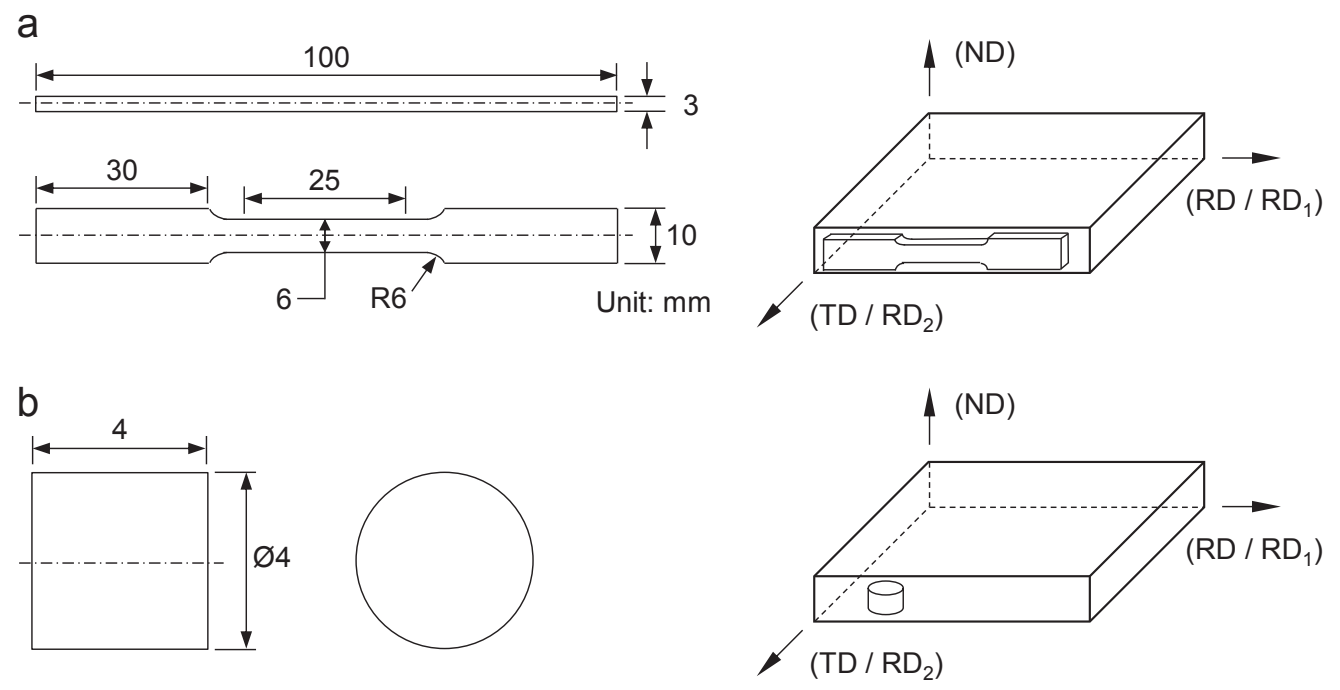

Fig. 1 Dimensions and orientation of (a) flat tension specimen and (b) cylindrical compression specimen.

a

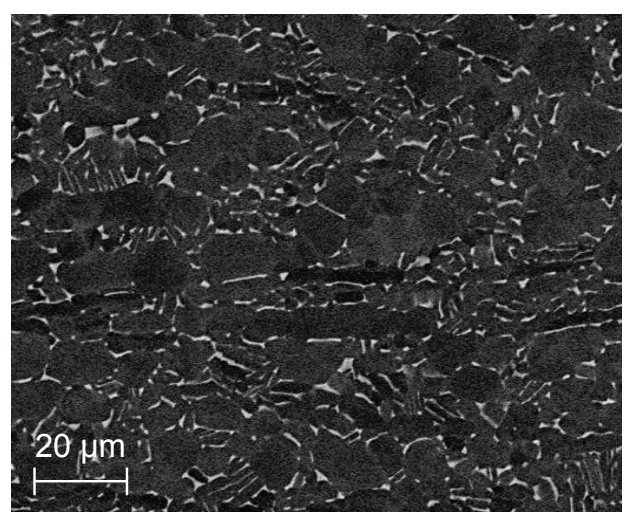

$\mathrm{b}$

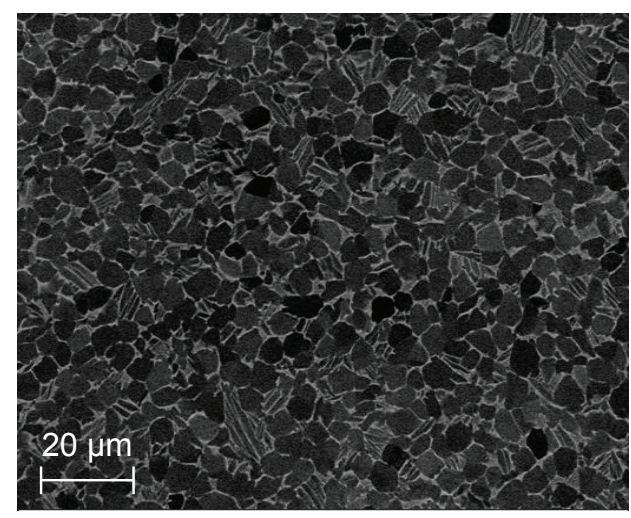

Fig. 2 SEM BSE images of the alpha (dark) and beta (bright) phases of (a) Ti64 and (b) Ti407 alloys in the TD plane. 

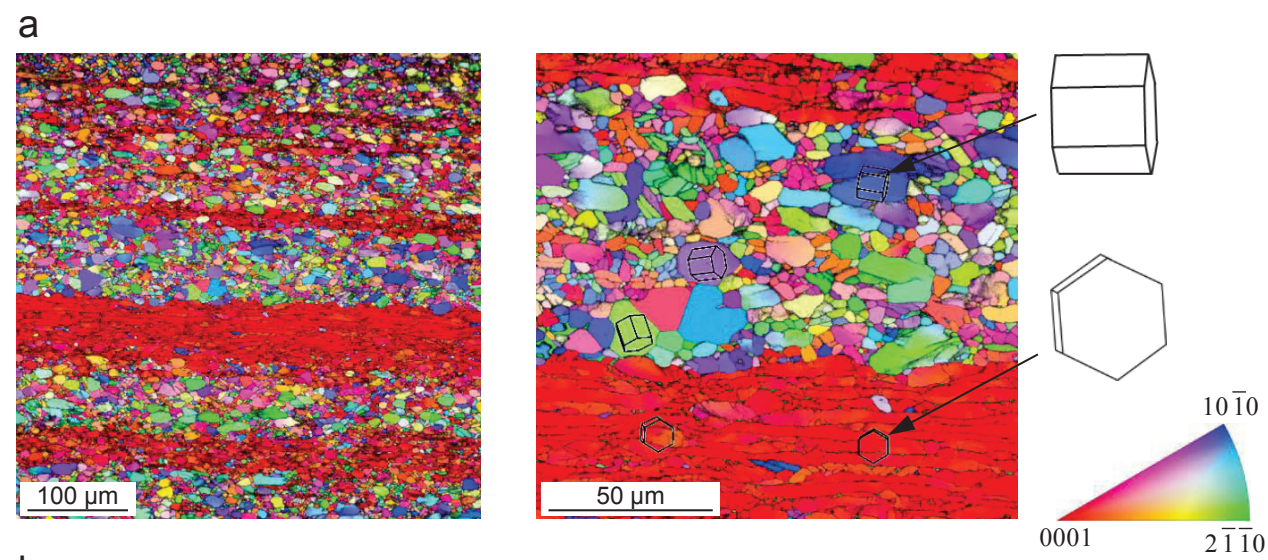

b
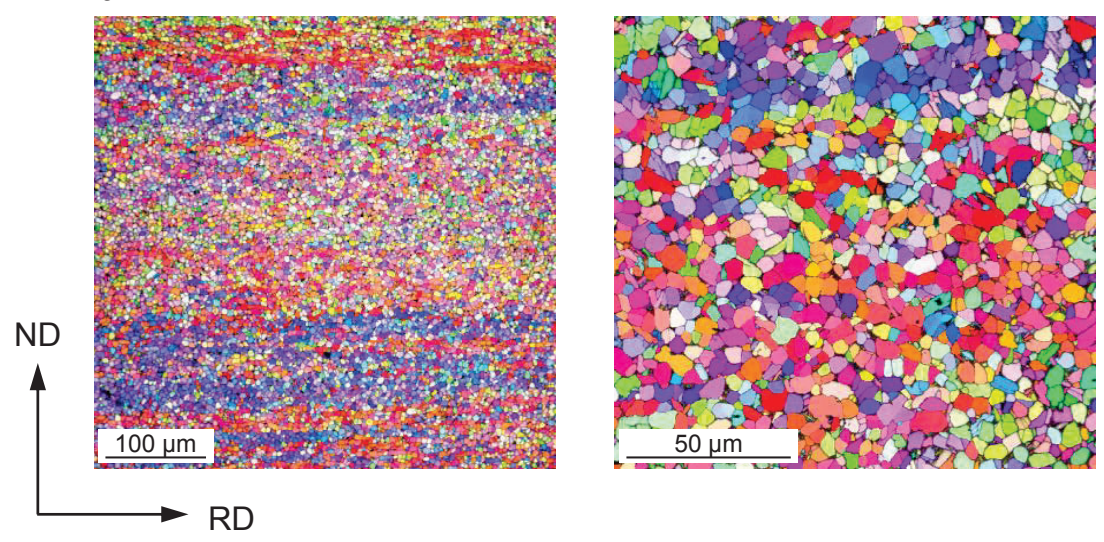

Fig. 3 EBSD inverse pole figures of (a) Ti64 and (b) Ti407 alloys in the TD plane at two different magnifications. 


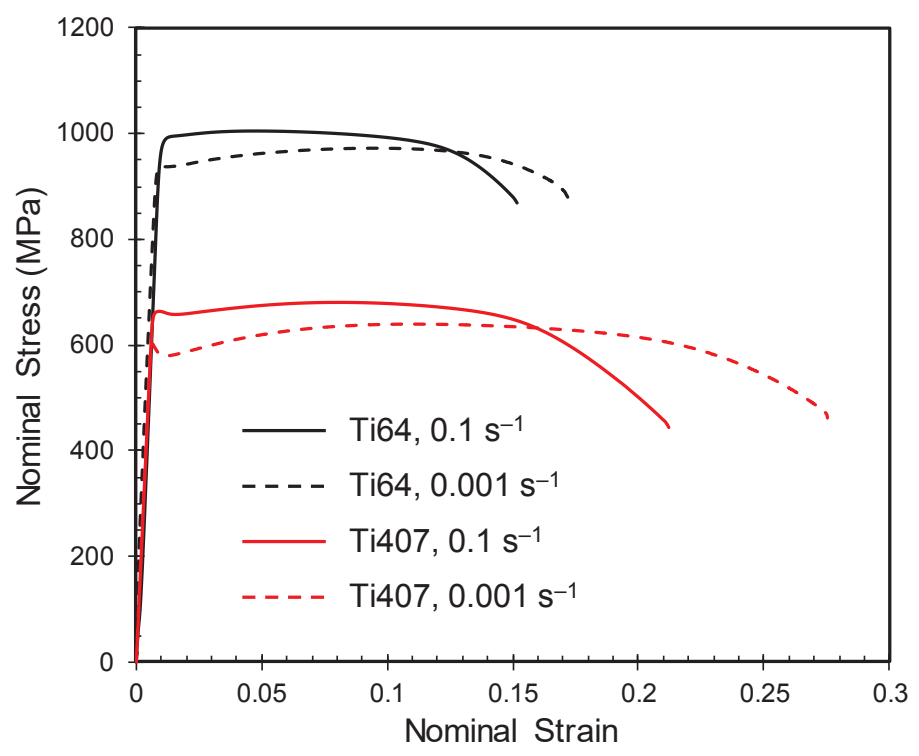

Fig. 4 Representative nominal stress-strain curves of Ti64 and Ti407 alloys under uniaxial tension at different strain rates.
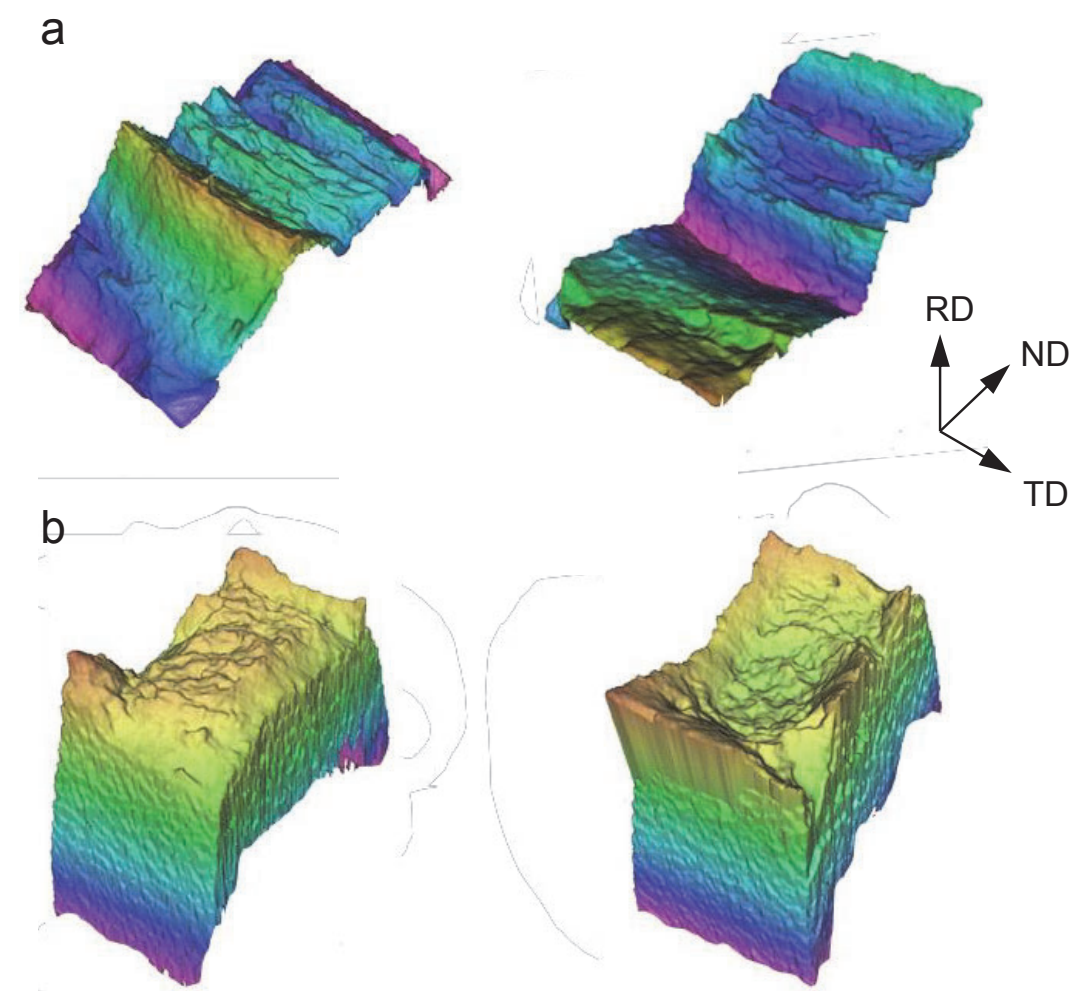

Fig. 53 p profiles of the two matching fracture surfaces of (a) Ti64 and (b) Ti407 alloys under uniaxial tension at the strain rate $0.001 \mathrm{~s}^{-1}$. 

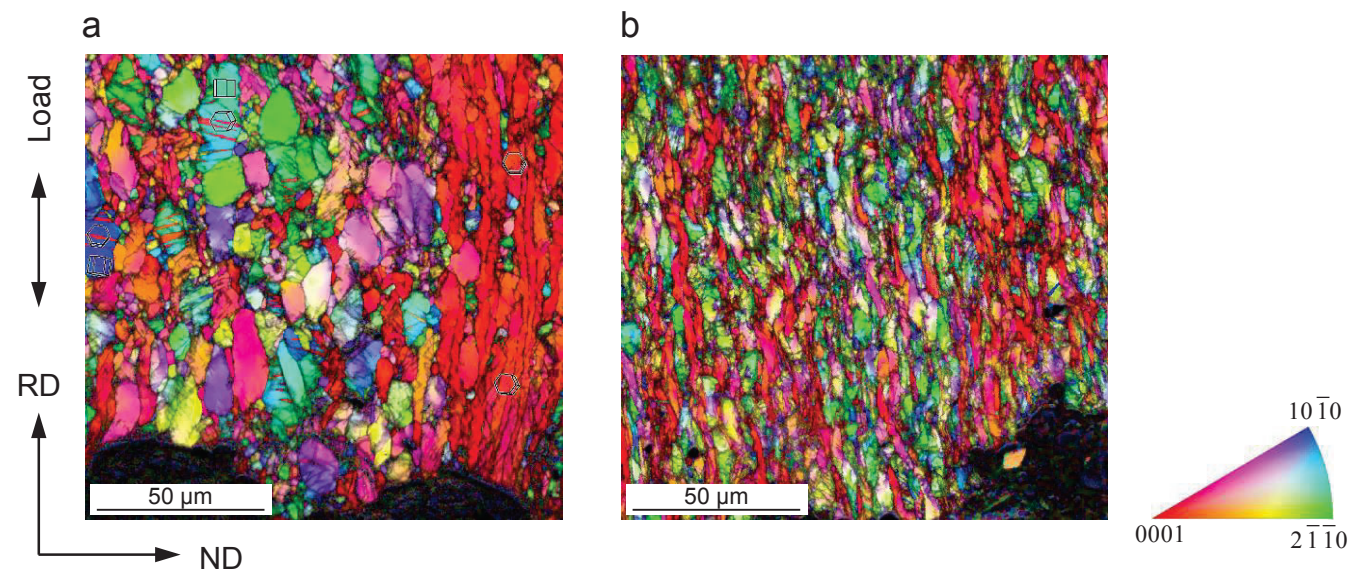

Fig. 6 EBSD inverse pole figures in the TD plane of (a) Ti64 and (b) Ti407 under uniaxial tension at the strain rate $0.001 \mathrm{~s}^{-1}$.

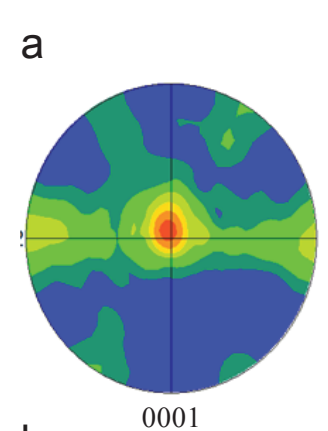

b

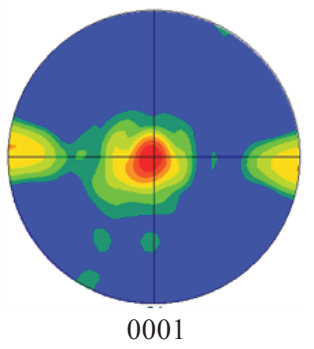

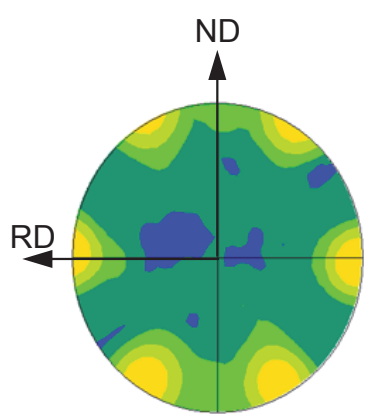

$10 \overline{1} 0$

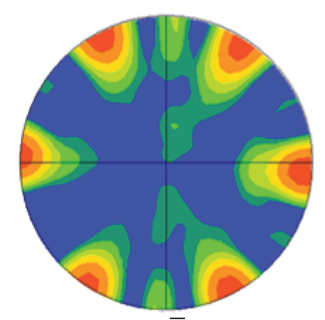

$10 \overline{1} 0$

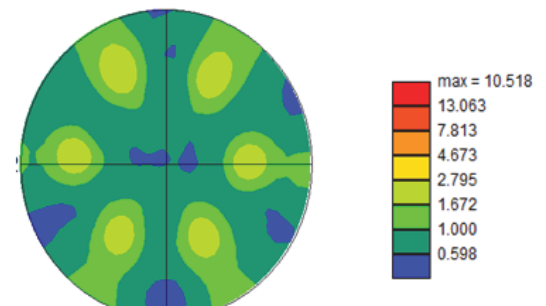

$10 \overline{1} 1$

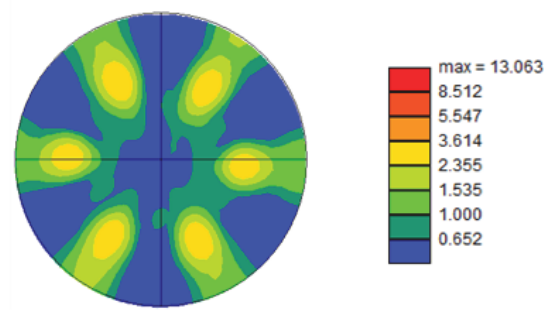

$10 \overline{1} 1$

Fig. 7 EBSD pole figures of Ti64 alloys: (a) undeformed and (b) under tension at the strain rate $0.001 \mathrm{~s}^{-1}$. At $1000 \times$ magnification. 


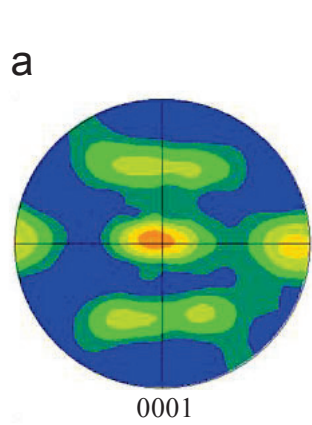

b

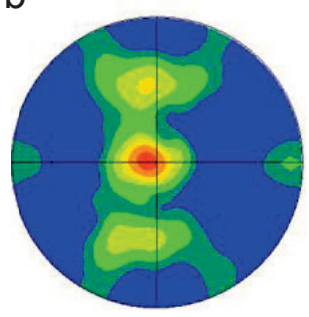

0001
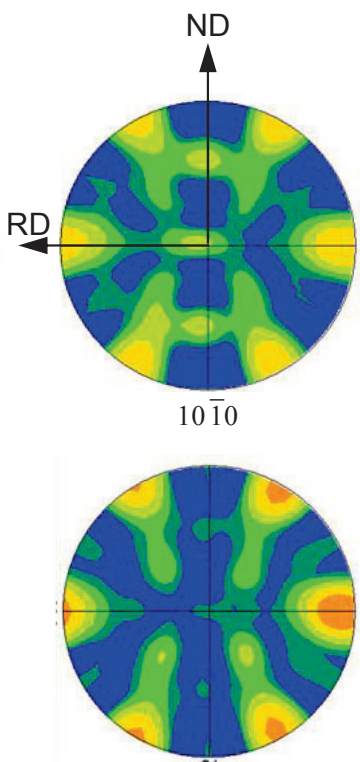

$10 \overline{1} 0$
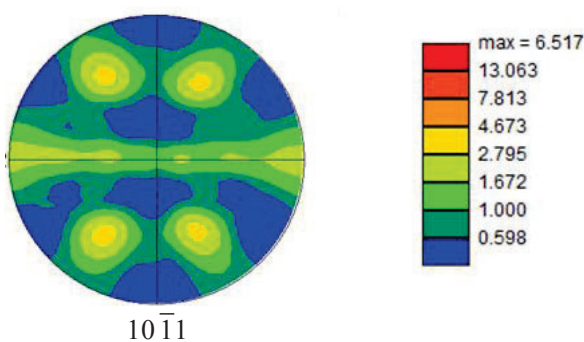

$10 \overline{1} 1$

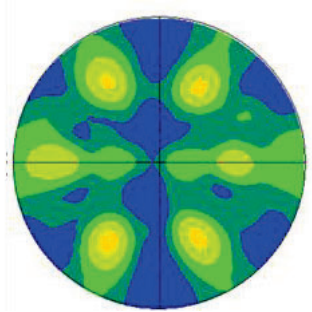

$10 \overline{1} 1$

Fig. 8 EBSD pole figures of Ti407 alloys: (a) undeformed and (b) under tension at the strain rate $0.001 \mathrm{~s}^{-1}$. At $1000 \times$ magnification.

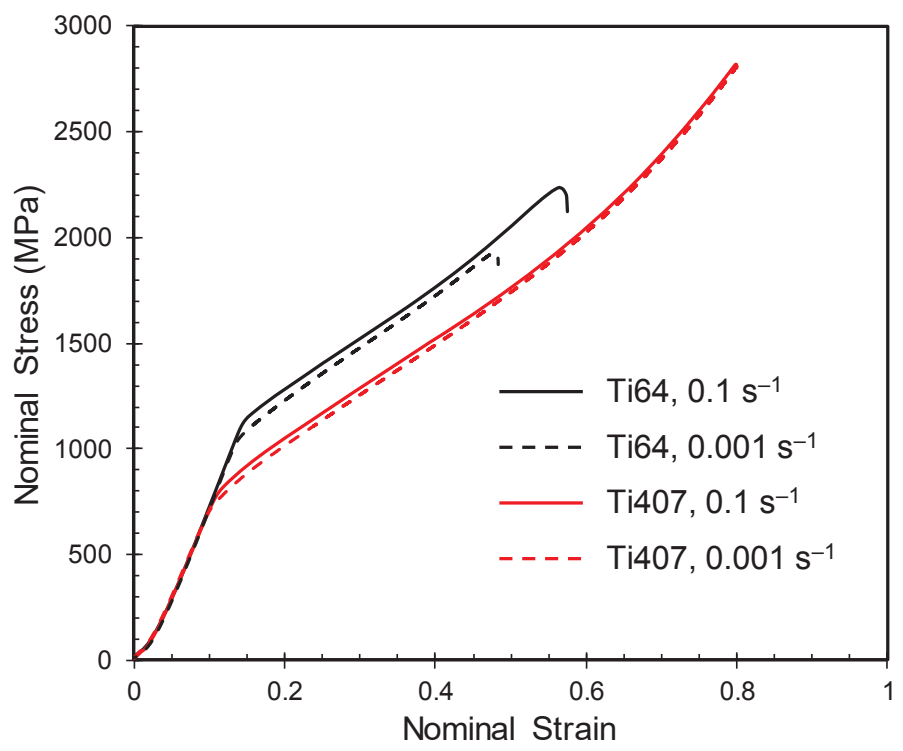

Fig. 9 Representative nominal stress-strain curves of Ti64 and Ti407 alloys under uniaxial compression at different strain rates. 

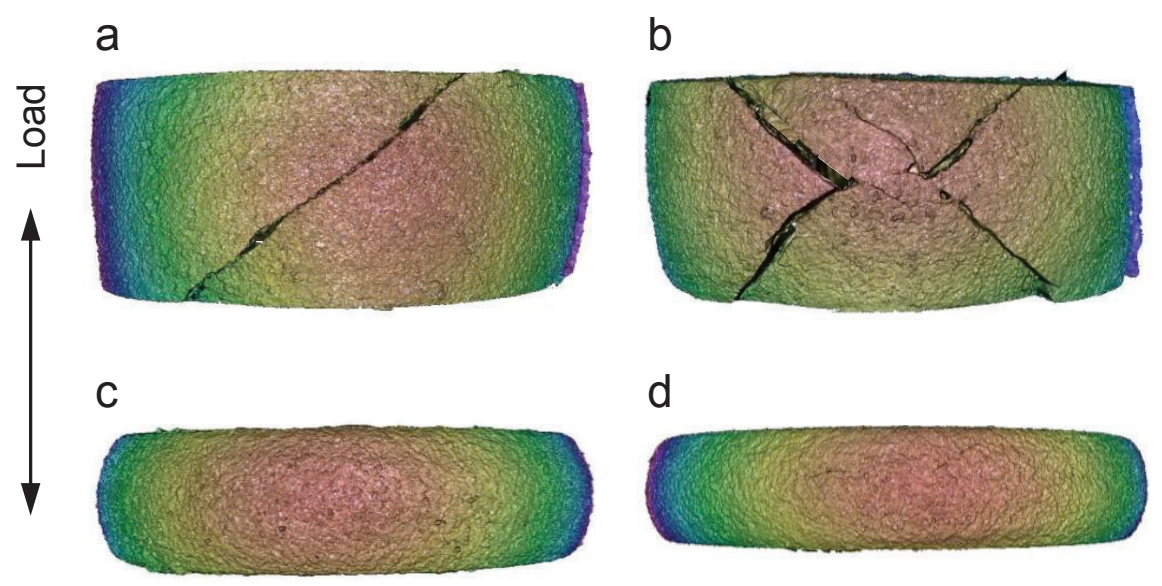

Fig. $103 \mathrm{D}$ surface profiles of titanium alloys subjected to uniaxial compression at different strain rates: (a) Ti64, $0.001 \mathrm{~s}^{-1}$, (b) Ti64, $0.1 \mathrm{~s}^{-1}$, (c) Ti407, $0.001 \mathrm{~s}^{-1}$ and (d) Ti407, $0.1 \mathrm{~s}^{-1}$.
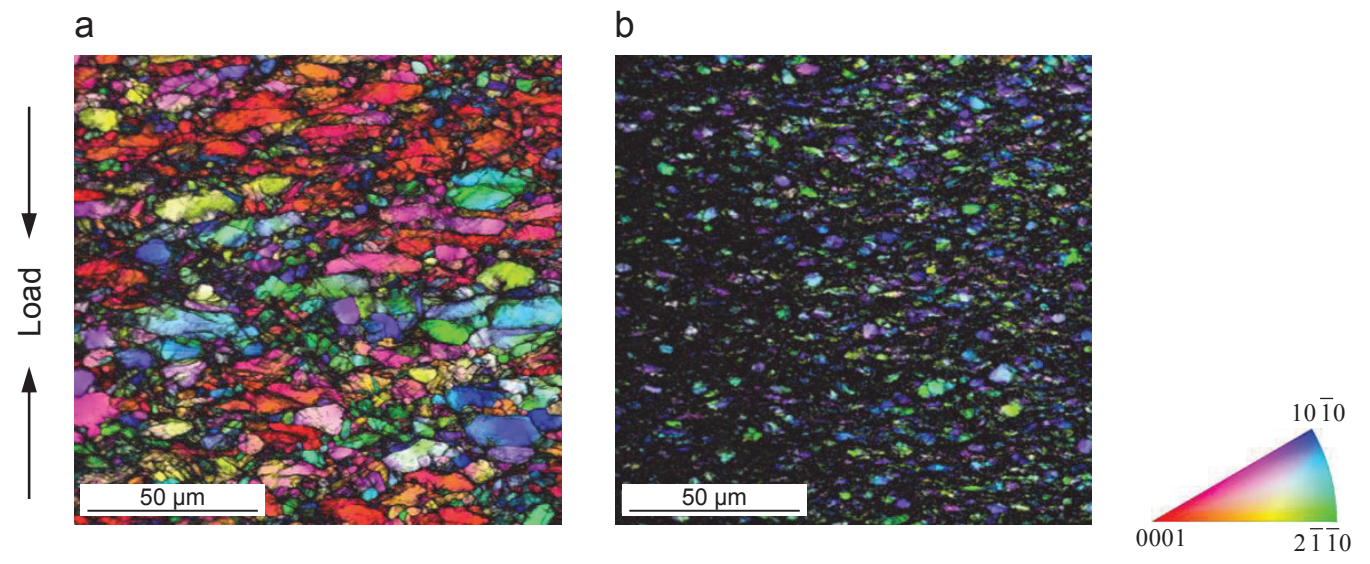

Fig. 11 EBSD inverse pole figures of (a) Ti64 and (b) Ti407 alloys subjected to uniaxial compression at strain rate $0.001 \mathrm{~s}^{-1}$. 